\title{
Study on Math Teaching and Cultivation of Students' Humanities Quality in Higher Vocational College
}

\author{
Xueguang Cao \\ Honghe Health Vocational College, Mengzi, Yunnan, 661199
}

Keywords: Higher vocational mathematics; humanistic quality; rationality

\begin{abstract}
At present, mathematics teaching in higher vocational colleges pays attention to the training of students' knowledge and skills, but ignores the cultivation of humanistic qualities. The cultivation of humanistic quality helps students to feel the rigorous beauty of mathematics, stimulate students' interest in learning, and improve their spiritual character. Therefore, in the teaching of mathematics in higher vocational schools, mathematics teachers should constantly improve their own humanistic qualities, explore the humanistic education factors in mathematics teaching materials, create a mathematical culture atmosphere outside the classroom, and cultivate students' humanistic qualities.
\end{abstract}

\section{Introduction}

Higher vocational mathematics courses play an important role in the cultivation of modern skilled talents. In addition to the basic knowledge, basic theories and basic concepts, mathematics teaching in higher vocational colleges must also focus on the concept of cultivating "people", infiltrating humanistic quality education in mathematics teaching, attaching importance to the cultivation of students' humanistic spirit, and making students truly Become a useful talent for the comprehensive development of mind and personality, and become a healthy development person.

\section{Current situation of mathematics teaching in higher vocational colleges}

With the continuous expansion of enrollment in higher vocational colleges, in order to ensure the source of students, the scores of higher vocational colleges are getting lower and lower, and the majority of students enrolled are poor, especially mathematics is worse. As a public basic course in higher vocational colleges, mathematics courses teach students basic mathematics. However, in recent years, some higher vocational colleges only pay attention to the cultivation of students' skills, and each major has continuously reduced the time of mathematics courses when formulating talent training programs. The author's survey of students in similar higher vocational colleges shows that learning professional knowledge, obtaining skills certificates, and finding a good job are the most important for them. More than half of the students believe that learning high-level courses does not help students improve their professional skills. Learning mathematics does not make sense.

Most of the mathematics textbooks in higher vocational colleges are compressed by the university's higher mathematics textbooks. The course content is mainly based on linear algebra, calculus, probability theory and mathematical statistics. Without considering the characteristics of higher vocational schools, the theoretical and intellectual knowledge of the textbooks is too much, but it ignores the extension and supplement of relevant knowledge. Improper teaching materials lead students to pay attention to mathematics classes. Some mathematics teachers have lost their way in teaching and do not know how to teach mathematics. Under this kind of understanding, some teachers who are engaged in the teaching of professional courses will pass the high-level mathematics knowledge when they encounter professional courses. They will not talk or talk less, just let the students keep in mind the results. These ultimately led to a cold class in mathematics courses in higher vocational colleges.

Mathematics has always been the main cultural force of human civilization. In ancient Greece, mathematics was part of philosophy; mathematics in our country was also included in the "six arts" 
(rite, music, shooting, imperial, book, number). However, some teachers now teach the basic concepts, principles and methods of higher mathematics in the classroom, but ignore the humanistic quality education function of higher mathematics. Mathematics is regarded as a tool, which is summarized into problem-solving technology and becomes A stylized thing. On the one hand, such mathematics teaching makes the students' knowledge is too narrow, lacks the development and innovation of the professionalism; on the other hand, it leads to the loss of some students' humanistic spirit and lack of enthusiasm and persistence in learning mathematics.

Humanistic quality education is to educate the outstanding cultural achievements accumulated by human beings through knowledge transfer, environmental cultivation and self-practice, and internalize them into temperament, cultivation and personality, and become a relatively stable internal quality education. Some higher vocational colleges are considering the employment rate. In order to spend more time studying professional courses and conducting practical classes, the mathematics courses are directly cancelled. Some institutions that offer higher vocational mathematics courses lack attention to subject knowledge. This not only affects the role of higher mathematics in the basic disciplines, but also restricts the follow-up of professional courses. In the end, the cultural education function of higher mathematics is difficult to play, and the goal of cultivating high-quality skilled talents in vocational colleges is difficult. achieve.

\section{The necessity of attaching importance to humanistic quality education in mathematics teaching in higher vocational schools}

"It is not enough to educate people with professional knowledge. Through professional education, he can become a useful machine, but he cannot become a harmonious development person, so that students have a new understanding of value (ie social ethics) and produce strong Feelings, that is the most basic." [1] Humanistic quality education is related to the growth of students, and plays a subtle role in cultivating students' cultural cultivation and moral quality. Therefore, in the process of higher vocational mathematics teaching, students should pay more attention to the humanistic quality education of students.

Mathematics is an important part of human culture. From the perspective of mathematics and culture, the history of mathematics development runs through higher mathematics, which is an important part of humanistic quality education in mathematics teaching. "Usually some textbooks are introduced in terms of seemingly unrelated courses. History provides an overview of the curriculum, linking the content of the curriculum and linking them to the backbone of mathematical thinking.” [2] In Mathematics In teaching, students should not only explain mathematics concepts and problem solving methods, but also enable them to quickly understand the systematic and organized mathematical principles and mathematical knowledge, as well as the history of mathematics development, which helps the students to form correctly. The mathematical view of understanding the role of mathematics in the process of human civilization.

The charm of mathematics is not only reflected in the rigorous and concise formula, but also in the rich content; not only in the ingenuity of the mathematical language form, but also in the diversity of the problem-solving methods. Mathematical content is abstract, but it can be either lively or vivid. In the mathematics teaching of higher vocational colleges, teachers can give students the enjoyment of mathematics beauty by teaching the brilliant achievements of mathematics development and showing the wide application of mathematics. Interspersed with humanistic quality education in the study of mathematics courses, students can gain a deeper understanding of the process of generating mathematical principles, and no longer regard higher mathematics courses as boring courses, including the charm of mathematics.

For higher vocational college students, advanced mathematics is a complicated and boring course. If in mathematics teaching, teachers will tell students about anecdotes about mathematics and mathematicians, such as Newton's growth experience and calculus. The history of development, the interesting little things of mathematicians, etc., reveal to students how a mathematical problem is proposed, what principles are used to solve it, what difficulties exist in the middle, or introduce some deeds that have made great achievements in mathematics. Guide students to explore in the 
ocean of knowledge, constantly stimulate and strengthen students' exploration psychology, and stimulate students' interest in learning.

Mathematics teaching is the teaching of mathematical thinking activities. If mathematics teachers in higher vocational colleges infiltrate the humanistic spirit in teaching, they can not only help students understand the ins and outs of higher mathematics thoughts, but also stimulate students' interest in mathematics. They can also influence students in a subtle way, not only let students know what to do, but also Let the students know why they are doing this and let them learn to express them in mathematical symbols and mathematical languages. Through the training of reverse thinking and reverse application formulas, students' ability of reverse thinking can be cultivated; through the training of multiple problems, the students' divergent thinking ability can be cultivated, so that students can learn to observe the world in a mathematical way of thinking in their work and life. change the world.

Mathematics can not only cultivate students' intellectual factors, but also help students form good non-intellectual qualities. If the mathematics curriculum only teaches students mathematics knowledge, it is easy for students to remember the concept principle and not understand the deep-seated things, which makes the students' independent thinking, innovation consciousness and rational thinking seriously lack of mathematical literacy. The goal of mathematics teaching is the transfer of knowledge, and it is to cultivate more three-dimensional people. Therefore, mathematics teaching not only requires students to learn some new methods of solving problems, but also infiltrates moral education and ethics, combines the instrumentality and humanity of mathematics education, combines truth-seeking and seeking good, and trains students. Humanistic quality and spirit.

In the mathematics teaching of higher vocational education, it is only the most basic teaching goal to let students master the solution to mathematics problems. What is more important is that students receive mathematics spirit and thought methods through learning mathematics, internalize them into wisdom, and put these good thinking qualities. Apply to all aspects of work, study and life. In the higher vocational mathematics teaching, only the function of humanistic education can cultivate the scientific spirit of students, promote the rational thinking of philosophy, cultivate the tenacious character of the will, reconstruct the quality education of humanities, and make the students form a perfect spiritual character.

\section{The methods and ways of implementing humanities quality education in higher vocational mathematics teaching}

In addition to focusing on promoting the professional development of students, mathematics courses in higher vocational colleges should also promote the development of students' individual abilities and assume the main tasks of cultivating students' abilities and literacy. Therefore, it is necessary to infiltrate the humanities quality education in the teaching of higher vocational mathematics, establish the educational concept of the integration of humanities and science through teacher training and environmental edification, and realize the harmony of humanistic spirit and scientific spiritual orientation.

Teachers are the creators and organizers of the teaching environment. The key to doing a good job in humanistic quality education lies in teachers. Regardless of whether the teachers are unconscious or not, when they impart knowledge and skills to the students, the human factors such as spiritual style, temperament, academic attitude and ideal pursuit reflected by their words and deeds will affect the students intentionally or unintentionally. In this sense, to improve the humanistic qualities of our teachers, we have the possibility to influence students.

Ancient and modern Chinese and foreign mathematics masters generally have cultural accomplishments that are no less than professional knowledge. Hua Luogeng loves literature and his life is obsessed with literature; Academician Wang Yikun is familiar with Chinese traditional culture and advocates the combination of mathematics and art; Leibniz has made his own contribution to calculus, and he is in politics, philosophy, law, linguistics. I left the work in other fields. Therefore, mathematics teachers must not only have sufficient professional skills, subject 
knowledge, and innovative consciousness, but also constantly learn cultural knowledge such as philosophy, history, and aesthetics to enrich their humanities. Only in this way, teachers can establish a good educational concept, in order to tap the potential of students while respecting the freedom and value of students, so that students can subtly accept humanistic quality education.

When a high-level student enters the school and begins to engage in advanced mathematics, how should mathematics teachers make students fall in love with mathematics and form a strong interest in learning? How to mobilize to enhance their enthusiasm for learning and confidence in learning? How to make students feel the charm of mathematics during the teaching process and realize the value and significance of mathematics? These should start with mathematics textbooks and related knowledge points, explore the elements that can be of interest to students, and explore the elements that allow them to continue learning.

The concept of definite integral in the content of mathematics textbooks, the division, the sum and the limit, vividly reflects the change law from quantitative change to qualitative change; the analytic geometry created by Descartes puts the two basic elements of mathematics "number" and "form" "Unified, this is an innovation; positive and negative in mathematics, constants and variables, finite and infinite, functions and inverse functions are vivid manifestations of dialectical thinking; simple and beautiful mathematical expressions, symmetrical beauty, geometric figures" It is the high-quality human factors that make students understand the beauty of mathematics and cultivate aesthetics. Therefore, teachers should seriously study mathematics teaching materials, grasp the structure of knowledge as a whole, clarify the context of humanistic quality education in mathematics textbooks, and form a relatively complete and reasonable humanistic quality training system.

To improve students' humanistic qualities in mathematics teaching, we must seize the main battlefield of classroom teaching. Teachers should carefully arrange the teaching content of the classroom, integrate the teaching content, and design the teaching form of teaching; teachers should explain the ins and outs of specific mathematical concepts, principles, ideas and problem-solving methods in the teaching, so that students can have multiple angles. The local experience and appreciation of their cultural level, feel the charm of mathematics and mathematical culture; teachers should encourage the curiosity, development, interaction and other means, the higher mathematics knowledge and mathematics culture seamlessly interface to achieve the common growth of teachers and students.

Students are in the digital age. The mathematics culture is filled around the students. They can use the campus newspaper, campus radio, campus network and other students to easily spread the mathematics culture and publicize the mathematics and humanities spirit. It can also build a higher mathematics network platform and upload some high-level mathematics platforms. Mathematical learning forums, mathematics test questions, mathematics history materials, and other math-related learning website links, so that students can solve problems in a timely manner, can learn independently and effectively; can also use the influence of the environment, in the process of campus culture construction Incorporating mathematical elements, teachers and students share resources and form a good humane atmosphere and campus culture. Teachers should encourage students to actively participate in learning in and out of the classroom, actively discover the law of exploration, actively acquire knowledge, and master the master of knowledge. This is an effective way to infiltrate humanistic quality education and cultivate innovative spirit in mathematics teaching.

\section{Conclusion}

Mathematics is an important part of human culture. It can help students train their minds and exercise their thinking skills. It enables students to realize their understanding of nature and society and to better integrate into this society. Infiltrating the humanistic spirit in college mathematics teaching is the inevitable trend of education and teaching reform in higher vocational colleges. This has great significance for improving the comprehensive quality, professional ability and sustainable development ability of students in higher vocational colleges. It will also produce students' life. 
Subtle influences. Therefore, higher vocational colleges should scientifically and reasonably integrate humanistic spiritual elements in the discipline setting and teaching plan according to the characteristics of mathematics itself, attach importance to the indoctrination of students' humanistic qualities, and enable students to accept the edification and baptism of mathematics culture and cultivate humanistic qualities.

\section{References}

[1] Ren Baoling. Mathematical culture education should be infiltrated in the teaching of basic mathematics courses in higher vocational colleges [J]. Adult Education, 2009 (3).

[2] Morris Klein. Ancient and Modern Mathematical Thoughts (Part 1) [M]. Translation by Zhang Lijing, Shanghai: Shanghai Science and Technology Press, 2002.

[3] Zheng Long et al. Introduction to Mathematical Thinking and Mathematical Methods [M]. Wuhan: Huazhong University of Science and Technology, 1999. 